\title{
Erratum to: Implementation of QFD method in quality analysis of confectionery products
}

\author{
Malgorzata Kowalska' ${ }^{1}$ - Magdalena Pazdzior ${ }^{2}$ • Anna Krzton-Maziopa ${ }^{3}$
}

Published online: 31 July 2015

(C) Springer Science+Business Media New York 2015

\section{Erratum to: J Intell Manuf \\ DOI 10.1007/s10845-015-1120-y}

Unfortunately, Fig. 1 was published in Polish version in the original publication of the article. The English version of Fig. 1 is published with this erratum.

The online version of the original article can be found under doi:10.1007/s10845-015-1120-y.

Malgorzata Kowalska

mkowalska7@vp.pl

1 Department of Chemistry, Faculty of Material Science, Technology and Design, Kazimierz Pulaski University of Technology and Humanities, Street Chrobrego 27, 26-600 Radom, Poland

2 Department of Design, Footwear and Clothing Technology, Faculty of Material Science, Technology and Design,

Kazimierz Pulaski University of Technology and Humanities, Street Chrobrego 27, 26-600 Radom, Poland

3 Chair of Inorganic Chemistry and Solid State Technology, Faculty of Chemistry, Warsaw University of Technology, Noakowskiego 3, 00-664 Warsaw, Poland 


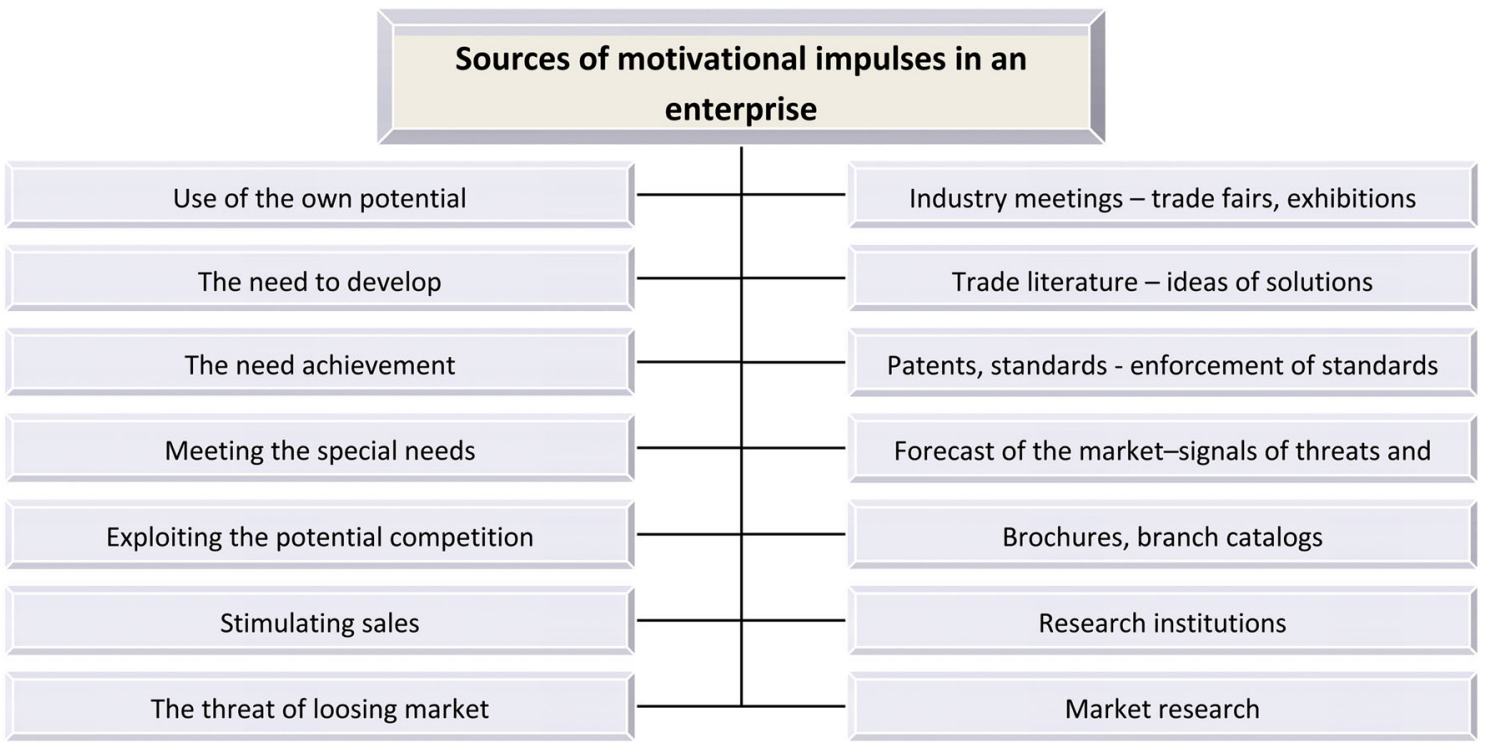

Fig. 1 Sources of motivation in an enterprise 